\title{
Application of Fuzzy Servqual Method to Measure User Satisfaction of Mooc Service Quality
}

\author{
Iqbal Firdaus ${ }^{1 *}$, Farikhin ${ }^{2}$, Bayu Surarso $^{3}$ \\ ${ }^{1}$ Magister Program of Information System, School of Postgraduate Studies, Diponegoro University, \\ Semarang - Indonesia \\ ${ }^{2}$ Department of Mathematics, Faculty of Science and Mathematics, Diponegoro University, Semarang \\ - Indonesia \\ ${ }^{3}$ Department of Mathematics, Faculty of Science and Mathematics, Diponegoro University, Semarang \\ - Indonesia
}

\begin{abstract}
To determine the level of success and effectiveness of MOOC in the learning system, it is important to measure the quality of service. The aim of this study is to measure the perceptions and expectations of MOOC users. The method of this study is the SERVQUAL model which is combined with a fuzzy approach, so that it can be measured accurately. From the calculation, the results show that Reliability dimension has the largest gap with a gap value $(-13,2325)$, so there are needed an improvement by the university. While Assurance dimension has the smallest gap with a value of gap $(-10,0025)$ this is considered by the user to be a better dimension than the others. From the calculation of the overall gap value obtained, the result shows a value of -57.65 , which means that the quality of service received by users is not in line with expectations.
\end{abstract}

\section{Introduction}

Now getting access to education and learning is effortless and trouble-free, it is all cannot be separated from the rapid development of technology. With the influence of technology, it provides broader space, accessible, and flexible in the learning procedure. Distancedlearning system is a way of teaching and learning that takes place without using interface process. The existence of distanced-learning systems aims to provide easy access to education and can reach wider community. This opportunity is used by many universities to organize distanced-learning systems as a support for conventional learning [1].

Massive Open Online Course (MOOC) is one of the alternative learning that is followed by many internet users. The reasons are MOOC is easy and inexpensive learning method as long as it is connected to the internet. MOOC describes an open class with large-scale access organized by the university using the internet. Like the regular online class, MOOC includes activities such as live video sessions, assignments, discussion forums and so on

* Corresponding author: iqbalfirdaus@students.undip.ac.id 
[2]. This makes MOOC considered a solution to the distribution of education as well as expanding access to quality education to all levels of society.

Padjadjaran University (Unpad) uses MOOC to support learning that can be accessed by many people and it is open to students and delivered by online. MOOC Unpad can be accessed by anyone, anytime and anywhere, so learning in Unpad can be accessed without having appearance to Unpad. Each user always expects to obtain optimal service. However, the lack of service quality can be one obstacle to the level of user satisfaction [3]. If this kind of thing is not responded quickly by the university, the result will decrease the interest from users to use MOOC from Unpad. Thus, it is necessary to measure the quality of service by involving users who use MOOC Unpad in order to know what aspects need to be focused and improved.

Satisfaction is one of the variables that is often found in service quality. The SERVQUAL model is a common method that is used to measure service quality. The SERVQUAL model is built on the gap between expectations and perceptions which means that the expected service is not the same as perceived by the customer's belief [4]. Subjective evaluation results will provide uncertain or unclear information. Fuzzy logic is an efficient method for dealing with situations that involve concept formation and pattern recognition in an undetermined or uncertain environment [5]. So in this study, Fuzzy servqual is used as a development method of service quality assessment to measure user satisfaction, so it can provide precise and accurate information.

\section{Methods}

\subsection{Fuzzy Logic}

Fuzzy logic is introduced by Lotfi A. Zadeh (1965) who coined that membership is a way to make decision when faced with the problem of uncertainty. The membership value of an item is at $[0,1]$, while in the fuzzy set membership value of an item is in between. Linguistic variables are important concept in fuzzy set theory, although they are less specific than numbers, but the information delivered is more informative. The advantage of using fuzzy logic is to dissemble the uncertainty and the lack of information [6]. Triangular Fuzzy Number (TFN) is used to overcome subjectivity and dissemble, so that problems in assessment can be overcome. TFN is stated with $\mu_{\bar{a}}(x): R \rightarrow[0,1]$ which has the membership function as follows [7]:

$$
\mu_{\bar{a}}(x)=\begin{array}{cc}
\frac{x-a_{1}}{a_{1}-a_{2}} & a_{1} \leq x \leq a_{2} \\
\frac{x-a_{3}}{a_{2}-a_{3}} & a_{2} \leq x \leq a_{3} \\
0 & \text { Otherwise }
\end{array}
$$

\subsection{SERVQUAL Model}

The quality of service can be interpreted as the comparison between the customer's belief and service perception. The SERVQUAL model developed by Parasuraman et al. (1985) is one of the most widely used service quality measurement models to identify gaps between customers and service providers [8]. In the SERVQUAL model, there are five dimensions of service quality which include aspects of tangibles, reliability, responsiveness, assurance, and empathy. Explanation of the five dimensions can be seen in table 1 [9]. 
Table 1. Explanation of SERVQUAL dimensions.

\begin{tabular}{|l|l|}
\hline \multicolumn{1}{|c|}{ Dimension } & \multicolumn{1}{c|}{ Explanation of SERVQUAL dimensions } \\
\hline Tangibles & The ability to display physical facilities and infrastructure \\
\hline Reliability & The ability to provide services as promised accurately and reliably \\
\hline Responsiveness & Willingness to help and provide fast and appropriate service to customers \\
\hline Assurance & The ability of service providers to grow the trust of customers \\
\hline Empathy & Give personal attention and understand the desires of customers \\
\hline
\end{tabular}

\subsection{Fuzzy SERVQUAL}

Fuzzy SERVQUAL is a way to measure service quality by using fuzzy numbers based on five service quality dimensions in the SERVQUAL model. Fuzzy SERVQUAL is used to overcome the problem of individual views that are uncertain or vague towards the assessment of desired perceptions and expectations. Fuzzy SERVQUAL calculation has 5 steps consisting of [10]:

\section{Step 1: Determine fuzzy sets for linguistic variables and measurement scales}

In this step each value given by the respondent on the questionnaire in each attribute will be calculated. The calculation is done on perception and expectations. The calculation is done using the following equation:

$$
A_{1}+A_{2}=\left(\alpha_{1}+\alpha_{2}, b_{1}+b_{2}, c_{1}+c_{2}\right)
$$

\section{Step 2: Determine fuzzy sets for linguistic variables and measurement scales}

In identifying user perceptions and expectations linguistic variables are used. Measurement scale used between 0 to 100 . Then change the scale value into fuzzy numbers, as shown in Table 2 .

Table 2. Linguistic variables for perception and expectation.

\begin{tabular}{|l|l|c|}
\hline $\begin{array}{c}\text { Linguistic } \\
\text { variable } \\
\text { (perception) }\end{array}$ & $\begin{array}{c}\text { Linguistic } \\
\text { variable } \\
\text { (expectation) }\end{array}$ & $\begin{array}{c}\text { Membership } \\
\text { function }\end{array}$ \\
\hline Very bad & Not at all important & $(0,0,25)$ \\
\hline Bad & Slightly Important & $(0,25,50)$ \\
\hline Fair & Moderately Important & $(25,50,75)$ \\
\hline Good & Very Important & $(50,75,100)$ \\
\hline Very good & Extremely Important & $(75,100,100)$ \\
\hline
\end{tabular}

\section{Step 3: Establishment of TFN value perceptions and value of user expectations}

The fuzzy calculation process is performed to form the TFN of the perceived value and the expected value of the user. Calculation to get the average weight of all users using the arithmetic mean with the following equation: 


$$
\begin{aligned}
\alpha_{m} & =\frac{\left(\alpha_{m 1}+\alpha_{m 2}+\alpha_{m 3} \ldots \alpha_{m i}\right)}{N} \\
b_{m} & =\frac{\left(b_{m 1}+b_{m 2}+b_{m 3} \ldots b_{m i}\right)}{N} \\
c_{m} & =\frac{\left(c_{m 1}+c_{m 2}+c_{m 3} \ldots c_{m i}\right)}{N}
\end{aligned}
$$

\section{Step 4: Get a single value from the average weight of each variable}

The next step confirms the fuzzification value obtained using the defuzzification calculation. The result of defuzzification will be the single value of the average weight of each variable. The defuzzification stage uses the following equation:

$$
X=\frac{\alpha_{m}+b_{m}+c_{m}}{3}
$$

\section{Step 5: Calculate the gap for each attribute}

The role of each attribute gap will show how important these attributes are in providing improved service quality. After getting the defuzzification value for perception and defuzzification for expectation, the gap for each attribute can be calculated using the following equation.

$$
\operatorname{Gap}_{i}=M A_{p i}-M A_{e i}
$$

\section{Implementation}

The initial step of this research is by designing a questionnaire. The questionnaire was made based on five dimensions in the SERVQUAL model, namely tangibles, reliability, responsiveness, assurance and empathy. Furthermore, distributing questionnaires via the internet containing each of the 20 attributes of perception and expectation questions. Then do the recapitulation of the results of the questionnaire that was filled by 100 respondents.

Table 3. Dimension and Attributes Question.

\begin{tabular}{|l|c|l|}
\hline Dimension & ID & \multicolumn{1}{|c|}{ Attribute Question } \\
\hline \multirow{4}{*}{ Tangibles } & Q1 & Attractive interface and colour design \\
\cline { 2 - 3 } & Q2 & Clearly visible menu and icon display \\
\cline { 2 - 3 } & Q3 & Easy-to-read text \\
\cline { 2 - 3 } & Q4 & Provides good video quality \\
\cline { 2 - 3 } & Q5 & Clear voice support \\
\hline \multirow{5}{*}{ Reliability } & Q6 & All links on the page are functioning correctly \\
\cline { 2 - 3 } & Q7 & Easy access to learning materials \\
\cline { 2 - 3 } & Q8 & Providing complete content services \\
\cline { 2 - 3 } &
\end{tabular}




\begin{tabular}{|c|c|l|}
\cline { 2 - 3 } & Q9 & Can run on different platforms \\
\hline \multirow{5}{*}{ Responsiveness } & Q10 & Sites can be accessed quickly \\
\cline { 2 - 3 } & Q11 & Responds faster to data access \\
\cline { 2 - 3 } & Q12 & Fast navigation menu \\
\cline { 2 - 3 } & Q13 & Rapid handling of system damage \\
\hline \multirow{5}{*}{ Assurance } & Q14 & Feel comfortable when using the site \\
\cline { 2 - 4 } & Q15 & Clear and intelligible learning system \\
\cline { 2 - 3 } & Q16 & Easy-to-use learning system \\
\cline { 2 - 3 } & Q17 & Adequate security system \\
\hline \multirow{5}{*}{ Empathy } & Q18 & The site understands user needs \\
\cline { 2 - 3 } & Q19 & Get feedback from the site \\
\cline { 2 - 3 } & Q20 & Sites respond to reports \\
\hline
\end{tabular}

In this step the, determination of the TFN is a range of values from the weight of the respondents answers. Each attribute is given a range of values to be calculated using Equation 3 for value c1, Equation 4 for value a1 and Equation 5 for value b1. From the results of fuzzification calculations for each attribute, the Defuzzification process is then performed to get a single value using Equation 6.

Table 4. Value of fuzzification and defuzzification.

\begin{tabular}{|c|c|c|c|c|c|c|c|c|}
\hline \multirow{2}{*}{ ID } & \multicolumn{4}{|c|}{ Perceptions } & \multicolumn{4}{c|}{ Expectations } \\
\cline { 2 - 6 } & \multicolumn{3}{|c|}{ Fuzzification } & \multirow{2}{*}{ Defuzzification } & \multicolumn{2}{c|}{ Fuzzification } & \multirow{2}{*}{ Defuzzification } \\
\cline { 2 - 6 } & $\mathbf{a}_{1}$ & $\mathbf{b}_{1}$ & $\mathbf{c}_{1}$ & & $\mathbf{a}_{1}$ & $\mathbf{b}_{1}$ & $\mathbf{c}_{1}$ & \\
\hline Q1 & 48 & 73 & 96 & 72,33 & 65,51 & 90,26 & 99 & 84,92 \\
\hline Q2 & 50 & 75 & 97,5 & 74,16 & 63,5 & 88,5 & 99,75 & 83,91 \\
\hline Q3 & 49,75 & 74,75 & 97 & 73,83 & 67,25 & 92,25 & 99,75 & 86,41 \\
\hline Q4 & 51 & 76 & 98,25 & 75,08 & 67 & 92 & 100 & 86,33 \\
\hline Q5 & 54,25 & 79,25 & 99,5 & 77,66 & 68,75 & 93,75 & 100 & 87,50 \\
\hline Q6 & 46,5 & 71,5 & 95 & 71,00 & 69,25 & 94,25 & 100 & 87,83 \\
\hline Q7 & 50,75 & 75,75 & 98,5 & 75,00 & 66,75 & 91,75 & 99,75 & 86,03 \\
\hline Q8 & 48,25 & 73,25 & 95,75 & 72,41 & 66 & 91 & 100 & 85,66 \\
\hline Q9 & 50,5 & 75,5 & 98,25 & 74,75 & 67,5 & 92,5 & 99,72 & 86,57 \\
\hline
\end{tabular}




\begin{tabular}{|c|c|c|c|c|c|c|c|c|}
\hline Q10 & 51,75 & 75,25 & 98,75 & 75,25 & 67,75 & 92,75 & 100 & 86,83 \\
\hline Q11 & 47 & 72 & 91 & 70,00 & 64,5 & 89,5 & 99,5 & 84,50 \\
\hline Q12 & 49,75 & 74,75 & 98 & 74,16 & 68,75 & 93,75 & 100 & 87,50 \\
\hline Q13 & 27,25 & 52,25 & 74,75 & 74,75 & 65,25 & 90,25 & 99 & 84,83 \\
\hline Q14 & 48,75 & 73,75 & 97 & 73,16 & 65 & 90 & 99,25 & 84,75 \\
\hline Q15 & 53,75 & 78,75 & 99,25 & 77,25 & 67 & 92 & 99,75 & 86,25 \\
\hline Q16 & 45,75 & 70,5 & 93,75 & 70,00 & 66,75 & 71,5 & 99,5 & 79,25 \\
\hline Q17 & 49,5 & 74,5 & 97,5 & 73,83 & 63,75 & 88,75 & 99,5 & 84,00 \\
\hline Q18 & 49 & 74 & 96,5 & 73,16 & 66,5 & 91,5 & 99,75 & 85,91 \\
\hline Q19 & 50,25 & 75,25 & 98,5 & 74,66 & 62,75 & 87,75 & 99 & 83,08 \\
\hline Q20 & 51,75 & 76,75 & 98,5 & 75,66 & 68 & 93 & 100 & 87,00 \\
\hline
\end{tabular}

In this step the gap value of each attribute is calculated which is the difference between perception and expectation using Equation 7. The value of the gap obtained plays a role in providing an evaluation of the extent to which these attributes provide satisfaction. Then rank from the highest value to the lowest value. So the university can find out whether the services provided are in line with the wishes of the students.

Table 5. Gap value of perceptions and expectations.

\begin{tabular}{|c|c|c|c|}
\hline ID & Perception & Expectation & Gap \\
\hline Q1 & 72,33 & 84,92 & $-12,59$ \\
\hline Q2 & 74,16 & 83,91 & $-9,75$ \\
\hline Q3 & 73,83 & 86,41 & $-12,58$ \\
\hline Q4 & 75,08 & 86,33 & $-11,25$ \\
\hline Q5 & 77,66 & 87,5 & $-9,84$ \\
\hline Q6 & 71 & 87,83 & $-16,83$ \\
\hline Q7 & 75 & 86,03 & $-11,03$ \\
\hline Q8 & 72,41 & 85,66 & $-13,25$ \\
\hline Q9 & 74,75 & 86,57 & $-11,82$ \\
\hline Q10 & 75,25 & 86,83 & $-11,58$ \\
\hline Q11 & 70 & 84,5 & $-14,5$ \\
\hline Q12 & 74,16 & 87,5 & $-13,34$ \\
\hline
\end{tabular}




\begin{tabular}{|c|c|c|c|}
\hline Q13 & 74,75 & 84,83 & $-10,08$ \\
\hline Q14 & 73,16 & 84,75 & $-11,59$ \\
\hline Q15 & 77,25 & 86,25 & -9 \\
\hline Q16 & 70 & 79,25 & $-9,25$ \\
\hline Q17 & 73,83 & 84 & $-10,17$ \\
\hline Q18 & 73,16 & 85,91 & $-12,75$ \\
\hline Q19 & 74,66 & 83,08 & $-8,42$ \\
\hline Q20 & 75,66 & 87 & $-11,34$ \\
\hline
\end{tabular}

\section{Result and Discussion}

Based on the calculation of the gap for each dimension, it was known that 20 attributes were negative. Attributes that had negative value mean that service quality had not met user expectations. Reliability dimension was ranked first with a value of $(-13,23)$ thus, it was needed a priority for improving service quality. The Assurance dimension ranked last with the value $(-10,00)$ which was better dimension than the others. From the results of the calculation, the gap as a whole showed that the negative gap value is -57.65 . it can be said that the quality of service expected by the user was not in accordance with what the user received.

Table 6. Rank of servqual Dimensions.

\begin{tabular}{|l|c|c|c|c|}
\hline \multicolumn{1}{|c|}{ Dimension } & Perception & Expectation & Gap & Rank \\
\hline Tangibles & 74,61 & 85,81 & $-11,20$ & 3 \\
\hline Reliability & 73,29 & 86,52 & $-13,23$ & 1 \\
\hline Responsiveness & 73,54 & 85,92 & $-12,38$ & 2 \\
\hline Assurance & 73,56 & 83,56 & $-10,00$ & 5 \\
\hline Empathy & 74,49 & 85,33 & $-10,84$ & 4 \\
\hline & 369,50 & 427,14 & $-57,65$ & \\
\hline
\end{tabular}

\section{References}

1 A. Gaskell, The evolution and evaluation of massive open online courses: MOOCs in motion, vol. 33, no. 1. (2018).

2 H. B. Shapiro, C. H. Lee, N. E. Wyman Roth, K. Li, M. Çetinkaya-Rundel, and D. A. Canelas, "Understanding the massive open online course (MOOC) student experience: An examination of attitudes, motivations, and barriers," Comput. Educ., vol. 110, pp. 35-50, (2017).

3 L. Ocampo et al., "Public service quality evaluation with SERVQUAL and AHPTOPSIS: A case of Philippine government agencies," Socioecon. Plann. Sci., vol. 68, 
(2019).

4 M. E. Souri, F. Sajjadian, R. Sheikh, and S. S. Sana, "Grey SERVQUAL method to measure consumers' attitudes towards green products - A case study of Iranian consumers of LED bulbs," J. Clean. Prod., vol. 177, pp. 187-196, (2018).

5 H. X. Li, Y. Wang, and C. L. P. Chen, "Dempster-Shafer structure based fuzzy logic system for stochastic modeling," Appl. Soft Comput. J., vol. 56, pp. 134-142, (2017).

6 C. Gupta, A. Jain, and N. Joshi, "Fuzzy Logic in Natural Language Processing - A Closer View," Procedia Comput. Sci., vol. 132, pp. 1375-1384, (2018).

7 A. Ijadi Maghsoodi, A. Saghaei, and A. Hafezalkotob, "Service quality measurement model integrating an extended SERVQUAL model and a hybrid decision support system," Eur. Res. Manag. Bus. Econ., vol. 25, no. 3, pp. 151-164, (2019).

8 M. S. Alam and M. Mondal, "Assessment of sanitation service quality in urban slums of Khulna city based on SERVQUAL and AHP model: A case study of railway slum, Khulna, Bangladesh," J. Urban Manag., vol. 8, no. 1, pp. 20-27, (2019).

9 S. Miranda, P. Tavares, and R. Queiró, "Perceived service quality and customer satisfaction: A fuzzy set QCA approach in the railway sector," J. Bus. Res., vol. 89, no. December, pp. 371-377, (2018).

10 R. Liu et al., "Applying the fuzzy SERVQUAL method to measure the service quality in certification \& inspection industry," Appl. Soft Comput. J., vol. 26, pp. 508-512, (2015). 